\title{
Linking toxicity and predation in a venomous arthropod: the case of Tityus fuhrmanni (Scorpiones: Buthidae), a generalist predator scorpion
}

\author{
Alejandra Arroyave-Muñoz ${ }^{1,2}$, Arie van der Meijden³, Sebastián Estrada-Gómez ${ }^{1,5}$ (1), Luis Fernando García** (1) \\ 'Toxinology Research Group - Serpentarium, University of Antioquia (UdeA), Medellín, Antioquia, Colombia. \\ ${ }^{2}$ Basic Sciences Development Program (PEDECIBA), University of the Republic, Iguá, Montevideo, Uruguay. \\ ${ }^{3}$ Research Center in Biodiversity and Genetic Resources (CIBIO), University of Porto, Vila do Conde, Portugal. \\ ${ }^{4}$ Eastern Regional University Center (CURE), University of the Republic, Treinta y Tres, Uruguay. \\ ${ }^{5}$ Center for Research in Natural Resources and Sustainability (CIRENYS), Bernardo O'Higgins University, Santiago, Chile.
}

\section{Keywords:}

Trophic ecology

$50 \%$ Lethal dose

Predatory behavior

Scorpions

Tityus

\begin{abstract}
Background: Scorpions are arachnids that have a generalist diet, which use venom to subdue their prey. The study of their trophic ecology and capture behavior is still limited compared to other organisms, and aspects such as trophic specialization in this group have been little explored.

Methods: In order to determine the relationship between feeding behavior and venom toxicity in the scorpion species Tityus fuhrmanni, 33 specimens were offered prey with different morphologies and defense mechanisms: spiders, cockroaches and crickets. In each of the experiments we recorded the following aspects: acceptance rate, immobilization time and the number of capture attempts. The median lethal dose of $T$. fuhrmanni venom against the three different types of prey was also evaluated.

Results: We found that this species does not have a marked difference in acceptance for any of the evaluated prey, but the number of capture attempts of spiders is higher when compared to the other types of prey. The immobilization time is shorter in spiders compared to other prey and the $\mathrm{LD}_{50}$ was higher for cockroaches.

Conclusions: These results indicate that T. fuhrmanni is a scorpion with a generalist diet, has a venom with a different potency among prey and is capable of discriminating between prey types and employing distinct strategies to subdue them.
\end{abstract}

* Correspondence: luizf.garciah@gmail.com https://doi.org/10.1590/1678-9199-JVATITD-2021-0036 Received: 31 March 2021; Accepted: 12 July 2021; Published online: 07 January 2022. 


\section{Background}

Predators often possess adaptations that enhance prey capture. These can include morphological, behavioral, and physiological adaptations. One of the most interesting adaptations for prey capture is the production of different types of secreted proteins that facilitate prey handling by leading to paralysis, death and sometimes pre-digestion of the prey $[1,2,3,4]$. The role of venom in prey capture has been studied most extensively in vertebrates such as snakes, where venom composition is related to diet breadth and has a high specificity against certain prey taxa $[5,6,7]$. Despite there being many more venomous groups of invertebrates than vertebrates, studies linking the predatory behavior and toxicity are limited among invertebrates.

In arthropods, most of the studies on the use of venom in the capture of prey have been carried out in spiders. For example, spiders were shown to regulate their venom use according to the type of prey and its resistance $[8,9,10]$. Venoms can also be highly specific, such as in spiders of the genus Zodarion that are specialized in ants [11]. Venoms can also have a broad spectrum in generalist predators, being effective against a wide variety of prey taxa, including vertebrates and invertebrates $[2,12]$. For example, venomous generalist predators like centipedes possess toxins able to overcome small vertebrates such as mice [13], but are also effective against other arthropods such as insects [14].

To understand the ecological role of venom and the selective pressures that have led to its target specificity, knowledge of the trophic niche and feeding ecology in venomous animals is particularly important. Understanding the relationship between the ecological function and target specificity of venom may also be medically relevant, as some studies hypothesize that toxicity towards humans in some arthropod predators might be a consequence of toxins that target vertebrates as prey [15]. Despite diet having a strong influence in some predatory venomous arthropods, the degree to which venoms are specialized to the preferred prey is still unknown in several groups.

At least three components can be directly associated with predation and defensive behaviors in scorpions: (1) morphology of the chelae and structure of the chelae fingers granulations; (2) morphology of the metasoma and in particular of the telson; (3) evolution of tegumentary glands in the telson toward different types of venom glands [16], the latter being one of the most studied aspects [17]. Despite venom playing a key role in prey capture, most studies have looked at the effect of venom from a defensive perspective in scorpions $[18,19,20,21]$. Some studies show that the venomous stinger is most used when capturing larger prey, suggesting venom could be optimized to handle difficult or potentially dangerous prey [22, 23, 24, 25].

Trophic ecology in scorpions has been poorly studied, with most studies based on relatively sparse field observations. Several of these studies show that scorpions are dietary generalists [26, $27,28,29]$. Only few studies have explored adaptations for prey capture. For example, Simone et al. [23] showed that females of the scorpion Bothriurus bonariensis display distinct prey capture strategies depending on prey type, and consume arthropods with contrasting morphologies and different defensive capabilities, while some other authors have shown intersexual variations on prey capture efficiency in some scorpion species [30]. Regarding trophic specialization, Toscano-Gadea and Costa [31], suggested that the scorpion Tityus uruguayensis might be a spider-specialist, given it has specific adaptations for capturing these prey.

The scorpion Tityus fuhrmanni (Krapelin 1914) is an endemic species of the Antioquia department in Colombia [32]. It causes a relatively high number of accidents in the city of Medellin [33]. Although some studies have covered some aspects of the biology of this species, such as life history, distribution, epidemiology, habitat and post-embryonic development [33, 34, 35], the feeding behavior of T. fuhrmanni has been poorly explored.

Since prey capture is strongly linked to venom composition in venomous predators, and given that scorpions depend on their venom delivery and composition to capture different prey, we expect that T. fuhrmanni may also possess specialized venoms to deal with certain prey types. If such specialization is present, we would expect the T. fuhrmanni to prefer certain prey, and handle those more successfully than others. However, if T. fuhrmanni have generalist trophic habits, as described by most previous studies in other scorpions, we expect a similar acceptance, predatory efficiency, and venom toxicity against all the evaluated prey. Therefore, the aim of this study is to compare prey acceptance, predatory efficiency, and venom toxicity in the scorpion T. fuhrmanni against different prey types: cockroaches, crickets and spiders. These prey possess different defensive strategies, such as fast movements in spiders and crickets, and venomous fangs in spiders, whereas cockroaches besides quick sprints possess tough cuticles too $[38,39,40]$. Overcoming such defensive strategies effectively may require a certain level of specialization by the predator.

\section{Methods}

\section{Specimen collection and housing}

We collected 33 individuals of Tityus fuhrmanni (9 males, 17 females and 7 juveniles) in Antioquia, Colombia, in a locality next to the village "El Salado" (6 $21^{\circ} 18.4^{\prime}$ N $75^{\circ} 28^{\prime} 50.4^{\prime}$ " W), and in the Medellín region on "El Volador" hill $\left(6^{\circ} 15^{\prime} 47.4^{\prime} \mathrm{N}\right.$ $75^{\circ} 34^{\prime} 55.3^{\prime}$ W). We selected these individuals based on their local abundance.

The Scorpions were deposited in the Serpetarium of the University of Antioquia, as part of the living collection (COLVIOFAR-149). After collection, specimens were kept individually in plastic terrariums $(21 \mathrm{~cm} \times 15 \mathrm{~cm} \times 6 \mathrm{~cm}$ height) with moist soil as a substrate and tree bark as a refuge. We also emulated the humidity $(70 \pm 10 \%)$, temperature $\left(22 \pm 5^{\circ} \mathrm{C}\right)$ and photoperiod (12-hour light/12-hour dark) of the sampling locality.

To select the prey types, we chose arthropods previously reported in the diet of other scorpion species [36], and that were sympatric with the local populations of T. fuhrmanni, namely, spiders (Ctenus sp., Araneae: Ctenidae), cockroaches (Periplaneta americana, Linnaeus, 1758, Blattodea: Blattidae) and crickets (Acheta domesticus Linnaeus, 1758, Orthoptera: Gryllidae). 
The latter were not the same species as encountered in the field, but are of the same genus, and similar in size and overall shape. Prey were selected based on their different morphology and defensive strategies, where crickets have fast movements, kicking and autotomy as their main defense mechanisms, cockroaches present a tough cuticle, while spiders can retaliate against the attack of potential predators by using their venomous chelicerae $[37,38,39]$. To avoid potential bias because of prey size, all prey were selected to be about three times larger than the size of the scorpion's prosoma (Table 1). Morphological measurements were made from digital photographs using the software imageJ version 1.8.0 [40].

\section{Prey acceptance and predatory behavior}

For this experiment, the 33 collected individuals ( 9 males, 17 females and 7 juveniles), were used. Before starting the experiments, the level of hunger was standardized for all scorpions. First, individuals were fed with Tenebrio molitor (Linnaeus, 1758, Coleoptera: Tenebrionidae) larvae to satiety for one day. Subsequently, the individuals were deprived of food for 27 to 29 days. This period of starvation was chosen based on our preliminary observations with a different cohort of scorpions.

Selected prey were randomly offered to scorpions following a random block design, where each prey individual is presented once to each scorpion individual, according to methods employed for similar predators such as spiders [41]. Random prey assignments were made using $\mathrm{R}$ software version 4.0.3 [42]. Before each experiment, both prey and scorpions were weighed and placed in an observation terrarium $(21 \mathrm{~cm} \mathrm{x} 15$ $\mathrm{cm} \times 6 \mathrm{~cm}$ height). Before the prey was introduced, scorpions remained in the observation terrarium for 20 minutes to allow them to habituate to the observation arena. Afterwards, prey was introduced at the opposite end of the scorpion's location in the observation arena. All experiments were recorded using a Canon Powershot sx 160 IS camera under red light illumination. This was done to avoid scorpion disturbance, given that red light is not perceived by scorpions [43]. In each experiment, we recorded interactions between scorpions and their prey for 40 minutes. If during that time prey was captured, it was considered accepted, otherwise it was considered rejected. All experiments were made during night since we recorded a highest activity for T. fuhrmanni during these period based on preliminary observations. Prey acceptance was compared using a Generalized Estimating Equation [44], with binomial distribution, with the prey type, starvation time and scorpion group (males, females and juveniles) as explanatory variables and the prey consumption as response variable. Individuals were included as a random variable. Mean length of the offered prey is described in Table 1.

We also recorded the number of attempts made by the scorpion before capturing the prey, defined as the number of times that scorpion tried to capture the prey using the pedipalps and their duration. Once captured, we also recorded the time it took for the scorpions to find a site to sting the offered prey, which started when the stinger first contacted prey's body. We measured the number of stings, their duration and the immobilization time, which was considered as the time from the first sting until the prey stopped moving. When analyzing the immobilization time, we used: number and duration of stings, prey:predator mass ratio and prey type as explanatory variables. The data was analyzed using a Generalized Estimating Equation with Gamma distribution using the immobilization time as response variable and the remaining variables were used as explanatory variables.

\section{Venom extraction}

To evaluate the potency of the venom against different types of prey, we obtained venom from twenty-two scorpions of $T$. fuhrmanni. We selected the largest individuals for each group, namely nine males, nine females, and four juveniles out of 33 individuals used for behavioral experiments. Given the low number of individuals, venom was pooled. Before conducting the experiments, scorpions were kept under laboratory conditions and fed with larvae of Tenebrio molitor. Venom was obtained according to the methodology of González-Gómez et al. [30], using a 12V electro-stimulator with a square wave signal at $40 \mathrm{~Hz}$ and a duty factor of $10 \%$. Both electrodes were applied at the metasoma, so that no current passes through vital organs or through the stinger, to avoid damage to the individual, or altering venom properties. Once extracted, the venom was stored at a temperature of $-20^{\circ} \mathrm{C}$ and lyophilized [45]. This research was approved by Ethics Committee for Animal Experimentation (CEEA), University of Antioquia Rectoral Resolution 18084, No. 123-2019.

\section{Toxicity bioassays}

To determine the median lethal concentration $\left(\mathrm{LD}_{50}\right)$ for the evaluated prey against T. fuhrmanni venom, we made preliminary observations using the same prey offered in behavioral experiments ( $\mathrm{n}=8$ individuals per each prey species). We used concentrations of $1.24 ; 2.5 ; 5 ; 10 ; 20 ; 30$ and $40 \mu \mathrm{g} / \mu \mathrm{L}$, based on reported $\mathrm{LD}_{50}$ values of different scorpion species used against arthropods $[46,47,48]$.

Table 1. Mean lengths of Tityus fuhrmanni and prey used in behavioral experiments: cockroaches (Periplaneta americana), crickets (Acheta domesticus) and spiders (Ctenus sp.).

\begin{tabular}{lccc}
\hline Common name & Body part & Species & Mean length \pm SD (mm) \\
\hline Scorpion & Prosoma & Tityus fuhrmanni & $5.39 \pm 0.79$ \\
Crickets & Body length & Acheta domesticus & $16.84 \pm 1.5$ \\
Cockroaches & Body length & Periplaneta americana & $16.68 \pm 2.07$ \\
Spiders & Body length & Ctenus sp. & $15.97 \pm 2.38$ \\
\hline
\end{tabular}


In order to regulate the dosage of the venom, we used insects and spiders with similar masses (variation coefficient $<6 \%$ ). Mean mass including variation coefficient and venom concentration are shown in Table 2. We selected consumed prey species instead of model organisms such as mice or Drosophila flies, since the latter may not be ecologically relevant for scorpions and produce biased results [49].

In each trial, we randomly selected one of the prey types, and the prey was exposed to a temperature of $0^{\circ} \mathrm{C}$ for approximately 30 seconds to put it in a temporary state of torpor. Then, a volume of $5 \mu \mathrm{L}$ of venom solution, dissolved in physiological saline $(0.9 \% \mathrm{NaCl}$ in purified water), was injected [50,51]. This procedure was repeated for all different concentrations and prey types (Table 2). As a control group we injected physiological saline solution without venom, we used 28 individuals in the control group for each prey type.

Venom injection was made in a place where no vital parts of prey were affected. It was applied in the coxa joint of leg III of the insects, while in the spiders the application was made in the coxae of leg IV. Application placement was chosen based on previous evidence which suggests that the process of application in the coxae joints itself does not cause death [15]. The injections were made with a $10 \mu \mathrm{L}$ Hamilton syringe. After the injection, individuals were placed in plastic boxes, with shelter and water ad libitum. Observations were made continuously for the first two hours to describe initial symptoms after injection, such as partial paralysis or tremors. At 24 hours and again at 48 hours after injection we recorded the number of dead individuals.
For the analysis of the $\mathrm{LD}_{50}$, we used a binomial generalized linear model with the individual's survival as response variable and prey type, and log-transformed concentration as explanatory variables with probit function as link [52].

\section{Results}

\section{Prey acceptance and predatory behavior}

We did not find a preference in T. fuhrmanni for any of the prey $\left(\chi^{2}\right.$ $=0.92, \mathrm{df}=1, \mathrm{p}=0.62$ ), or between males, females and juveniles $\left(\chi^{2}=2.35, \mathrm{df}=2, \mathrm{p}=0.12\right)$. We also did not find a significant effect of starvation time on acceptance $\left(\chi^{2}=2.72, \mathrm{df}=1, \mathrm{p}=0.09\right)$. Acceptance for all offered prey was higher than 70\% (Figure 1). However, the number of capture attempts was significantly higher $\left(\chi^{2}=48.50, \mathrm{df}=2, \mathrm{p}<0.01\right)$ for spiders compared to other prey such as cockroaches (contrasts: $\mathrm{p}<0.01$ ) and crickets (contrasts: $\mathrm{p}<0.01)$. In the majority of cases $(74 \%)$, scorpions pinched spiders by their legs, which were autotomized allowing them to escape (Additional file 1). In addition, the spiders made rapid escape movements and sometimes tried to bite the scorpions when attacked. Significant differences were also found between cockroaches and crickets (contrasts: $p=0.04$ ). The number of capture attempts was higher for cockroaches (Figure 2), which made fast evasive movements when attacked, while crickets were quickly subdued (see Additional files 2 and 3 ).

When evaluating the immobilization time, we found that neither the body mass of the prey $\left(X^{2}=0.6, \mathrm{df}=1, \mathrm{p}=0.42\right)$,

Table 2. Mean body mass and coefficient of variation for prey used in $\mathrm{LD}_{50}$ experiments. Used prey were: cockroaches (Periplaneta americana), crickets (Acheta domesticus) and spiders (Ctenus sp.), including the number of used individuals (n).

\begin{tabular}{|c|c|c|c|c|c|}
\hline Common name & Species & $\begin{array}{c}\text { Concentration } \\
(\mu g / \mu L)\end{array}$ & $\begin{array}{l}\text { Mean weight } \\
\quad \pm \text { SD (g) }\end{array}$ & $\begin{array}{l}\text { Coefficient } \\
\text { of variation }\end{array}$ & $\mathbf{n}$ \\
\hline \multirow[t]{3}{*}{ Cockroach } & Periplaneta americana & 0 & $0.35 \pm 0.017$ & 5.39 & 28 \\
\hline & & 40 & $0.34 \pm 0.020$ & 5.93 & 15 \\
\hline & & 60 & $0.35 \pm 0.016$ & 4.75 & 15 \\
\hline \multirow[t]{4}{*}{ Cricket } & Acheta domesticus & 0 & $0.35 \pm 0.019$ & 5.39 & 28 \\
\hline & & 10 & $0.36 \pm 0.014$ & 3.94 & 15 \\
\hline & & 20 & $0.38 \pm 0.020$ & 4.79 & 15 \\
\hline & & 30 & $0.40 \pm 0.020$ & 5.46 & 15 \\
\hline \multirow{2}{*}{ Spider } & & 20 & $0.36 \pm 0.015$ & 4.25 & 15 \\
\hline & & 30 & $0.35 \pm 0.014$ & 3.85 & 15 \\
\hline
\end{tabular}




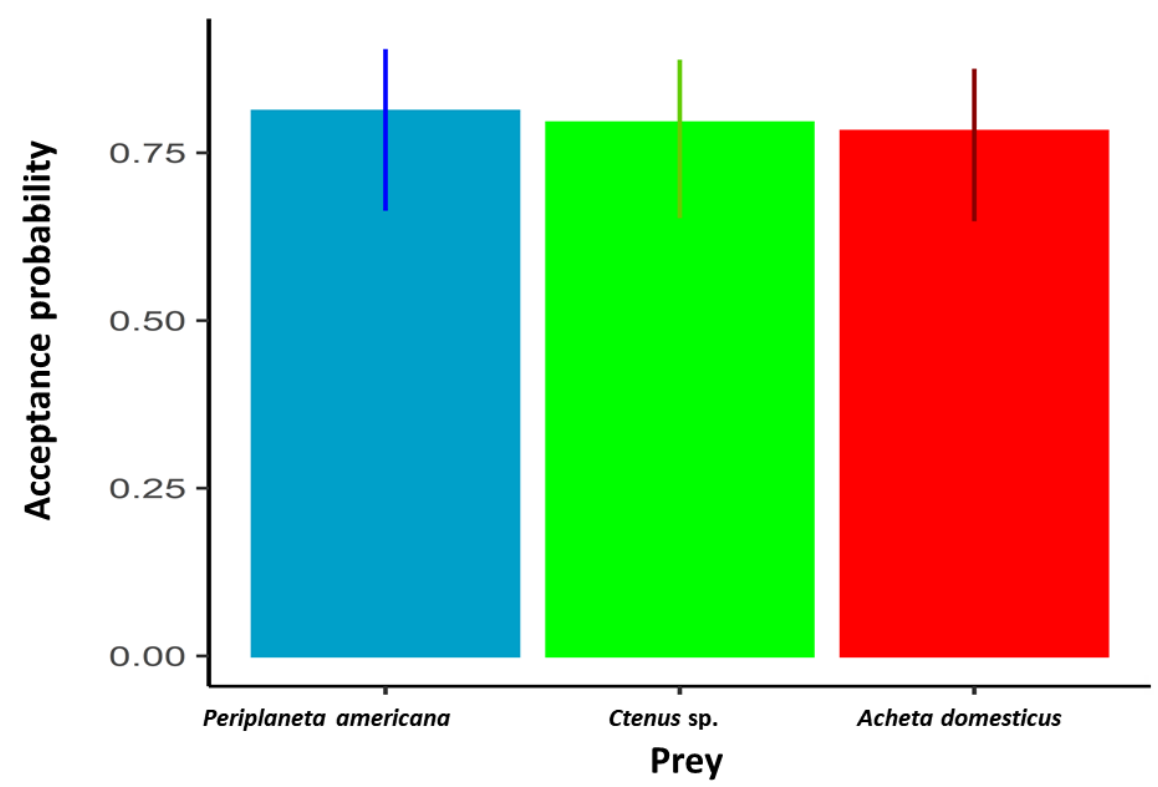

Figure 1. Acceptance probability of Tityus fuhrmanni of spiders (Ctenus sp.), crickets (Acheta domesticus) and cockroaches (Periplaneta americana). Bars represent means, lines are $95 \%$ confidence intervals. Mean values and confidence intervals were estimated using a generalized estimating equation with a binomial distribution.

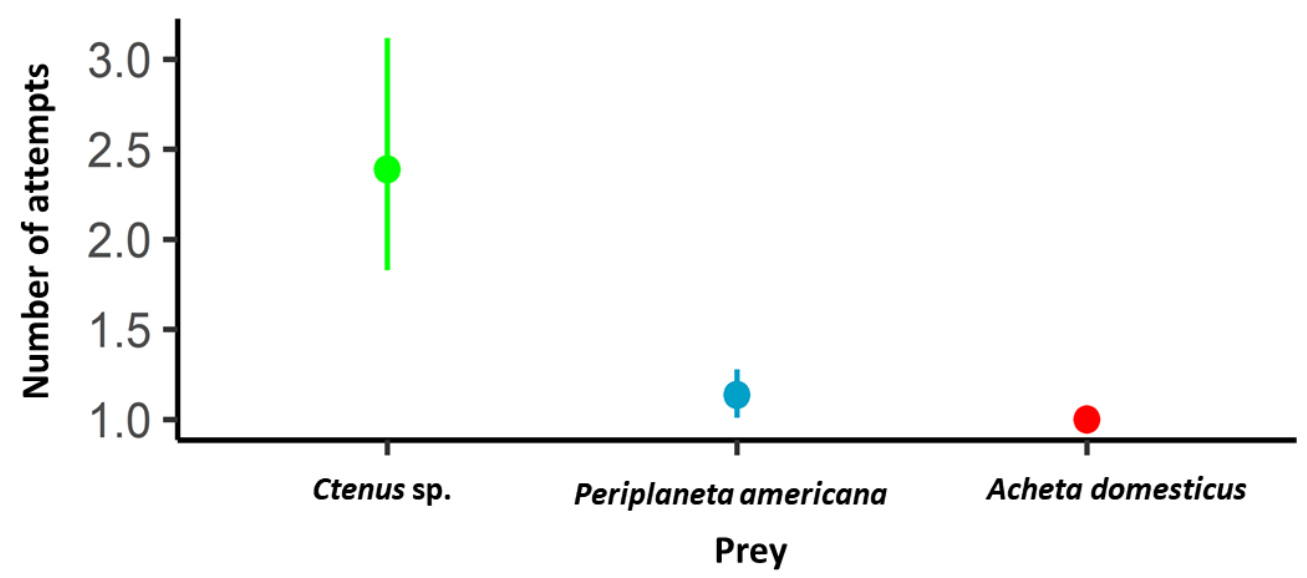

Figure 2. Number of attempts employed by Tityus fuhrmanni when capturing spiders (Ctenus sp.), crickets (Acheta domesticus) and cockroaches (Periplaneta americana). Points represent means, lines are $95 \%$ confidence intervals. Mean values and confidence intervals were estimated using a generalized estimating equation with a Poisson distribution.

nor the total duration of stinging $\left(\chi^{2}=0.4, \mathrm{df}=1, \mathrm{p}=0.50\right)$ had a significant effect on the immobilization time. The immobilization times were significantly different between prey $\left(\chi^{2}=83.7, \mathrm{df}=\right.$ $2, \mathrm{p}<0.01$ ), being lower in spiders compared to crickets and cockroaches. No significant differences were observed between the remaining prey (Figure 3). We also found significant differences in immobilization times regarding the number of stings $\left(\chi^{2}=9.6, \mathrm{df}\right.$ $=1, \mathrm{p}=0.02)$. It is noteworthy that spiders and crickets received two stings at most to be paralyzed, while some cockroaches needed up to three stings before being immobilized. We found a significant effect of the interaction between the type of prey and the number of stings on the immobilization time $\left(\chi^{2}=7.0, \mathrm{df}=2\right.$, $p=0.03$ ). The interaction occurred because the immobilization time decreased with the number of stings in crickets, while it increased in cockroaches and showed a slight increase in spiders.

\section{Toxicity bioassays}

Toxicity was significantly different between prey types $\left(\chi^{2}=\right.$ $60.60, \mathrm{df}=2, \mathrm{p}=0.038)$, we also recorded a significant effect of dosages on mortality $\left(\chi^{2}=36.50, \mathrm{df}=1, \mathrm{p}<0.039\right)$. When evaluating differences in prey type, we found that cockroaches were the most resistant prey to T. fuhrmanni venom, followed by crickets, with values close to significance $(p=0.07)$ but more resistant than spiders (contrasts: $p=0.027$ ). We found that spiders and crickets were similarly affected by the scorpion venom (contrasts: $p=0.32$ ). None of the individuals in the control group died for any of the prey types. The $\mathrm{LD}_{50}$ curves are reported in Figure 4, while $\mathrm{LD}_{50}$ values are shown in Table 3. Although not quantified, behavioral effects of venoms were observed shortly after injection, including tremors in all prey, as well as vomiting in crickets. 


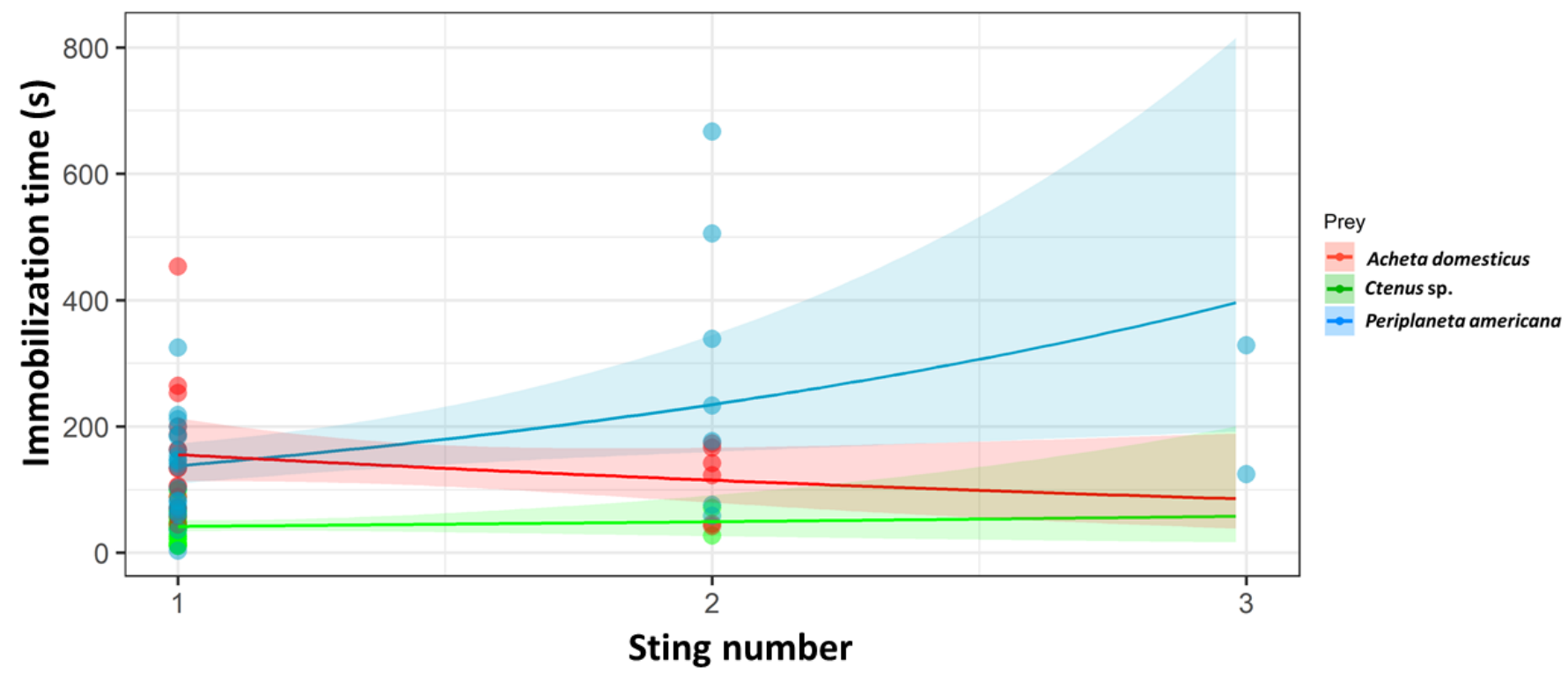

Figure 3. Relationship between immobilization time and sting number of Tityus fuhrmanni when capturing spiders (Ctenus sp.), crickets (Acheta domesticus) and cockroaches (Periplaneta americana). Shaded bands represent confidence intervals. Lines and confidence intervals were estimated using a generalized estimating equation with a gamma distribution.

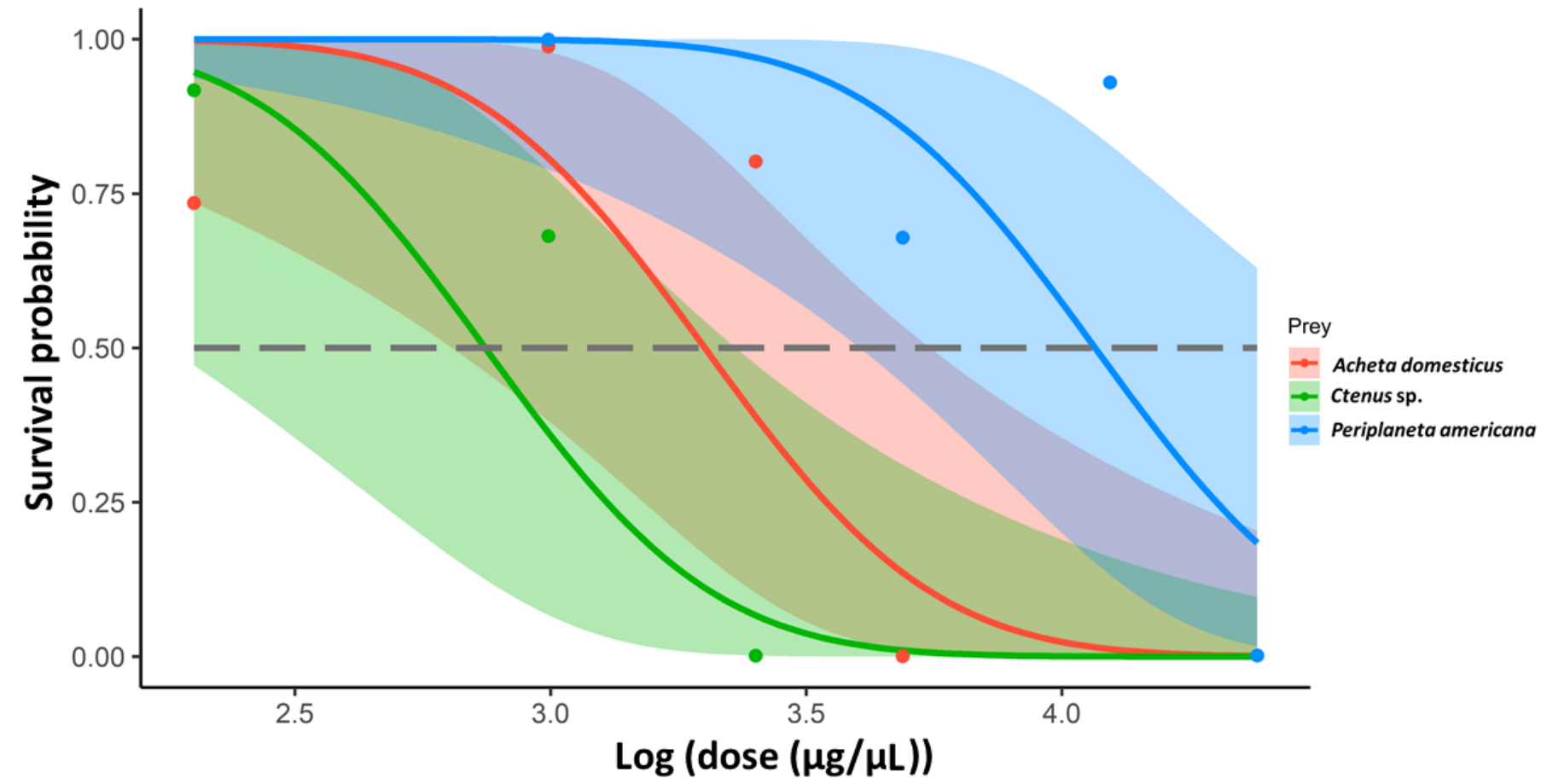

Figure 4. The survival curves as a function of $\log ($ dose). Median lethal dose expressed as mg of venom per $\mathrm{kg}$ of prey are expressed in Table 3. Shaded bands represent confidence intervals. All parameters were estimated using a binomial generalized linear model.

Table 3. Estimated $\mathrm{LD}_{50}$ values for each prey type.

\begin{tabular}{|c|c|c|c|}
\hline Common name & Species & $\begin{array}{c}\operatorname{LD}_{50}(\log (\text { dose }) \pm \text { standard } \\
\text { error })\end{array}$ & $\mathrm{LD}_{50}(\mathrm{mg} / \mathrm{kg})$ \\
\hline Spider & Ctenus sp. & $2.88 \pm 0.02$ & 249.91 \\
\hline Cricket & Acheta domesticus & $3.30 \pm 0.02$ & 376.35 \\
\hline Cockroach & Periplaneta americana & $4.09 \pm 0.02$ & 846.07 \\
\hline
\end{tabular}




\section{Discussion}

Our results indicate that the scorpion T. fuhrmanni can overcome and feed on prey types with contrasting morphologies such as cockroaches, crickets and spiders. The fact that the scorpions consumed all offered prey types in similar proportions suggests they do not have a specific preference. A similar trend was observed for males, females and juveniles, which accepted prey in very similar proportions. However, given the limited number of individuals used, further studies should explore if prey acceptance varies according to the instar on this species. The ability to capture prey with contrasting morphologies observed in T. fuhrmanni agrees with previous studies, which describe other scorpion species as being dietary generalists $[23,27,28,29]$ However, further studies evaluating capture of prey with different morphologies to confirm the trends observed in our study, may be valuable. All the accepted prey have been previously reported as common prey for other scorpion species under natural conditions. Given their sympatric habits, these prey types are likely also an important part of the diet of T. fuhrmanni.

Interestingly, we found that T. fuhrmanni employs a higher number of prey capture attempts when preying on spiders. This agrees with the report by Simone et al [23], who found that bothriurid scorpions needed more attempts to capture spiders compared to other prey. Probably the higher number of attempts recorded in spiders may be due to appendage autotomy, which is a defensive strategy frequently used by spiders [53]. Wolf spiders for instance, increase their survival probabilities by autotomizing some legs when attacked by scorpions [54]. Our results corroborate that autotomy may be an effective defensive strategy for spiders when attacked by scorpions, since the ctenid spiders used in our study often removed their legs when attacked by scorpions, and these proceeded to consume them before a next attempt at capture. In addition, some of the spiders tried to bite the scorpions while being attacked and displayed fast bouts of locomotion when the scorpion approached. Nevertheless, we did not record any successful bite of the spiders towards the scorpions. These behaviors combined might explain the high number of attempts necessary for scorpions to capture spider prey. Interestingly, cockroaches were the second hardest prey to capture for the scorpions, which might be explained by their fast movements. The high speed of cockroaches makes them a difficult prey for some predators like frogs [55].

We expected that longer stinging durations would allow the scorpions to inject more venom, which would be reflected in shorter immobilization times. However, this was not the case. We suppose that the lack of relationship between immobilization time and duration of sting could have occurred since some of the stings might have not been effective or may even have been "dry", as reported in some species which use defensive stings [21,23], or to minimize venom expenditure such as has been shown for some scorpion species [17]. In contrast, we found a significant interaction between the number of stings and the immobilization times and prey type. During behavioral experiments, both spiders and crickets needed up to two stings to be paralyzed. In the case of crickets, the immobilization time decreased as the number of stings increased. However, although showing low immobilization times, we found a slight correlation between the immobilization and the number of stings in Ctenus sp. This is probably a consequence of the spider defensive behavior that prevented an efficient injection of venom in some cases. During the venom injection bioassays, we found that both spiders and crickets are equally susceptible to scorpion venom and therefore this similar sensitivity to the venom may lead them to be paralyzed in similar times. It must be noted that $\mathrm{LD}_{50}$ does not directly record time to paralysis, but is used here as a general indication of sensitivity to the venom. Further studies regarding venom sensitivity should include prey paralysis time when different dosages are used. The immobilization times for the spiders during the behavioral experiments were shorter than for the other prey. We presume that this occurred because spiders are potentially dangerous prey, with a high retaliation capacity and therefore, they must be paralyzed quickly [56]. Potentially, scorpions used more venom against this prey, and/or the lower $\mathrm{LD}_{50}$ values for spiders resulted in faster immobilization after being stung. This has also been suggested for other venomous predators when subduing difficult prey. A reduced contact time between a predator and a potentially dangerous prey reduces the probability of injury to the former [57]. Interestingly, in cockroaches the number of stings increased with time of immobilization. These results are consistent with similar studies that show longer immobilization times for cockroaches when preyed upon by Phoneutria spiders [15]. We observed a similar trend, which we presume is due to the scorpion having difficulties when trying to sting the cockroaches, since the tough cuticle of this prey prevented the stinger from penetrating. A similar trend has been observed in some Loxosceles spiders, as well as in other scorpions, when attacking armored arthropods such as harvestmen [58]. Although we expected a significant effect of mass on immobilization time in scorpions, as in other predatory venomous arthropods such as spiders [15], this was not the case, probably as we used prey with similar mass ranges.

The $\mathrm{LD}_{50}$ results agreed with our immobilization time observations, since dosages needed to kill cockroaches after experimental injection were higher compared to spiders and crickets. Although venom resistance in cockroaches was similar to crickets, values close to significance suggest that by adding more individuals, significant differences might be found. A high resistance to venoms as well as other toxins has been reported for cockroaches [59, 60], including other scorpion species [61], which might also explain why scorpions needed more stings to subdue this prey type. In addition to the armored body of cockroaches, the venom resistance might explain why the number of stings was positively correlated with the immobilization time. In the case of crickets and spiders, toxicity assays showed similar values, but immobilization time was different for these prey when captured by the scorpion. These results indicate that scorpions are probably able to dose venom depending on the prey type. Given that spiders are a more dangerous prey than crickets, it is possible that scorpions inject more venom to paralyze this prey more quickly to prevent possible injuries. Such venom metering for more dangerous prey also occurs in other venomous predators such as snakes or spiders [10, 62]. 
Trends recorded in our study are similar to those recorded in other buthid species such as Centruroides edwardsii [61], where Periplaneta were also more resistant to scorpion venom than $A$. domesticus Interestingly $\mathrm{LD}_{50}$ values found in our study for $T$. fuhrmanni were lower for A. domesticus than other scorpions such as $C$. edwardsii. Although $\mathrm{LD}_{50}$ values might have been affected by using T. fuhrmanni specimens kept under laboratory conditions for long periods, our results are consistent with those reported by Gómez et al [33], who suggested that T. fuhrmanni venom is less toxic to insects than other buthid species.

Given that the venom was able to incapacitate unrelated arthropods, such as insects and spiders, our results suggest it is not specific against a particular prey type group. However, these results should be interpreted carefully as differences in toxicity between crickets and spiders were close to significance. Additional studies should explore if this is the case for other buthid scorpions. Further studies should evaluate if the toxicity against vertebrates found in this scorpion genus might be due to selection for vertebrate prey, as has been suggested for other predatory arthropods, such as belostomatid bugs, spiders, and centipedes $[13,15,63]$, or even other scorpion species [61].

\section{Conclusion}

Our results show that the scorpion T. fuhrmanni is a generalist and potentially euryphagous predator able to overcome and consume a variety of prey besides spiders. Although venom affected all evaluated prey, it had a different potency depending on the animal. It is probable that the scorpion is able to dose venom for potentially dangerous prey, which would be interesting to evaluate in future studies.

Traditionally, $\mathrm{LD}_{50}$ studies on venomous arthropods such as spiders or scorpions are focused on model organisms, like mice or Drosophila flies, which have little or no ecological relevance for the studied venomous animal $[15,50,65]$. In the present study we showed a link between toxicity and prey capture, using potentially sympatric prey of the scorpion T. fuhrmanni. Although one of the prey species we used was not sympatric and local prey may have specific adaptations, such as resistance to venom that may not be evolved in laboratory-reared prey as occurs with some snake prey [65] - the other prey types were confirmed sympatric species. Evaluating toxicity using sympatric prey is particularly important. Toxicological arms-races between predator and local prey may explain the toxicity in medically important arthropods, as has been suggested for Phoneutria and Latrodectus spiders $[15,64]$. These results show the importance of multidisciplinary studies that include both behavioral, as well as toxicological approaches, to understand predator-prey relationships. Further studies should also explore if a similar trend occurs in other scorpion species. Similarly, other aspects of the prey, such as mobility and metabolism should be considered in further toxicological studies, as these aspects may explain part of the effect of venom on different prey.

\section{Acknowledgments}

We thank the staff of the Serpentarium of the Universidad de Antioquia: Janet Lucia Garcia, Jorge Enrique Aspirlla and Sergio Kubides. We are also indebted to David Gallo because of his help with scorpions sampling. We thank Stano Pekár for his advice on statistical analyses.

\section{Availability of data and materials}

The datasets generated during and/or analyzed during the current study are available from the corresponding author on request.

\section{Funding}

This research was funded by the Universidad de Antioquia (UdeA) through the project CIQF-284. AvdM was financed through FCT - Fundação para a Ciência e a Tecnologia, I.P., under contract number DL57/2016/CP1440/CT0009. LFG was funded by Agencia Nacional de Inestigación e Innovación (ANII) and full time program (DT) by the Comisión Sectorial de Investigación Científica.

\section{Competing interests}

The authors declare that they have no competing interests.

\section{Authors' contributions}

AAM, LFG and SEG conceived this research and designed experiments. AAM, LFG, and AVDM wrote the main manuscript. AAM and SEG carried out all the experiments. AAM and LFG analyzed all the data. All authors reviewed and approved the final manuscript.

\section{Ethics approval}

All animal care was in accordance with appropriate ethical guidelines. The present study was approved by the Comite de Ética para Experimentación en Animales de la Universidad de Antioquia (CEEA, University of Antioquia - Resolución Rectoral 18084), minute no. 123-2019.

\section{Consent for publication}

Not applicable.

\section{Supplementary material}

The following online material is available for this article:

Additional file 1. Video of the scorpion Tityus fuhrmanni capturing a Ctenus sp. spider.

Additional file 2. Video of the scorpion Tityus fuhrmanni capturing an Acheta domesticus cricket.

Additional file 3. Video of the scorpion Tityus fuhrmanni capturing a Periplaneta americana cockroach. 


\section{References}

1. Edmunds MC, Sibly RM. Optimal. Sting use in the feeding behavior of the scorpion Hadrurus spadix. J Arachnol. 2010;38(1):123-5.

2. Fuzita FJ, Pinkse MW, Patane JS, Verhaert PD, Lopes AR. High throughput techniques to reveal the molecular physiology and evolution of digestion in spiders. BMC Genomics. 2016 Sep 7;17(1):716.

3. Carregari VC, Rosa-Fernandes L, Baldasso P, Bydlowski SP, Marangoni S, Larsen MR, Palmisano G. Snake Venom Extracellular vesicles (SVEVs) reveal wide molecular and functional proteome diversity. Sci Rep. 2018 Aug 13;8(1):12067.

4. Schendel V, Rash LD, Jenner RA, Undheim EA. The diversity of venom: the importance of behavior and venom system morphology in understanding its ecology and evolution. Toxins. 2019 Nov;11(11):666.

5. da Silva Jr NJ, Aird SD. Prey specificity, comparative lethality and compositional differences of coral snake venoms. Comp Biochem Phys C Toxicol Pharmacol. 2001 Mar;128(3):425-56.

6. Davies EL, Arbuckle K. Coevolution of snake venom toxic activities and diet: evidence that ecological generalism favours toxicological diversity. Toxins. 2019 Dec 6;11(12):711.

7. Lyons K, Dugon MM, Healy K. Diet breadth mediates the prey specificity of venom potency in snakes. Toxins (Basel). 2020 Jan 23;12(2):74.

8. Boevé JL, Kuhn-Nentwig L, Keller S, Nentwig W. Quantity and quality of venom released by a spider (Cupiennius salei, Ctenidae). Toxicon. 1995 Oct;33(10):1347-57.

9. Malli $\mathrm{H}$, Kuhn-Nentwig L, Imboden $\mathrm{H}$, Nentwig W. Effects of size, motility and paralysation time of prey on the quantity of venom injected by the hunting spider Cupiennius salei. J Exp Biol. 1999 Aug;202(15):2083-9.

10. Wigger E, Kuhn-Nentwig L, Nentwig W. The venom optimisation hypothesis: a spider injects large venom quantities only into difficult prey types. Toxicon. 2002;40(6):749-52.

11. Pekár S, Toft $\mathrm{S}$, Hrušková M, Mayntz D. Dietary and prey-capture adaptations by which Zodarion germanicum, an ant-eating spider (Araneae: Zodariidae), specialises on the Formicinae. Naturwissenschaften. 2008 Mar;95(3):233-9.

12. Bleckmann $\mathrm{H}$, Lotz $\mathrm{T}$. The vertebrate-catching behaviour of the fishing spider Dolomedes triton (Araneae, Pisauridae). Anim Behav. 1987 Jun;35(3):641-51.

13. Luo L, Li B, Wang S, Wu F, Wang X, Lian P, Ombati R, Chen J, Lu X, Cui J, Lu Q, Zhang L, Zhou M, Tian C, Yang S, Lai R. Centipedes subdue giant prey by blocking KCNQ channels. PNAS. 2018 Feb 13;115(7):1646-51.

14. Yang S, Liu Z, Xiao Y, Li Y, Rong M, Liang S, Zhang Z, Yu H, King GF, Lai R. Chemical punch packed in venoms makes centipedes excellent predators. Moll Cell Proteomics 2012 Sep;11(9):640-50.

15. Valenzuela-Rojas JC, González-GómezJC, Guevara G, Franco LM, ReinosoFlórez G, García LF. Notes on the feeding habits of a wandering spider, Phoneutria boliviensis (Arachnida: Ctenidae). J Arachnol. 2020;48(1):43-8.

16. Lourenço WR. The coevolution between telson morphology and venom glands in scorpions (Arachnida) J Venom Anim Toxins incl Trop Dis. 2020;26:e20200128. https://doi.org/10.1590/1678-9199JVATITD-2020-0128.

17. Evans ER, Northfield TD, Daly NL, Wilson DT. Venom costs and optimization in scorpions. Front Ecol Evol. 2019 Jun 6;7:196.

18. Niermann CN, Tate TG, Suto AL, Barajas R, White HA, Guswiler OD, Secor SM, Rowe AH, Rowe MP. Defensive Venoms: Is Pain Sufficient for Predator Deterrence? Toxins. 2020;12(4):260.

19. Casper GS. Prey capture and stinging behavior in the emperor scorpion, Pandinus imperator (Koch) (Scorpiones, Scorpionidae). J Arachnol. 1985;13(3):277-83.

20. Nisani Z, Hayes WK. Defensive stinging by Parabuthus transvaalicus scorpions: risk assessment and venom metering. Anim Behav. 2011 Mar;81(3):627-33.

21. Van der Meijden A, Coelho P, Rasko M. Variability in venom volume, flow rate and duration in defensive stings of five scorpion species. Toxicon. 2015 Jun 15;100:60-6.

22. Cooper AM, Nelsen, DR, Hayes WK. The strategic use of venom by spiders. Evol Venom Anim Their Toxins. 2015 Jul 28:1-18.
23. Simone Y, Garcia LF, Lacava M, van der Meijden A,Viera, C. Predatory versatility in females of the scorpion Bothriurus bonariensis (Scorpiones: Bothriuridae): Overcoming prey with different defensive mechanisms. J Insect Behav. 2018 Jun 1;31(4):402-15.

24. Coelho PL, Kaliontzopoulou A, Rasko M, van der Meijden A. A 'striking'relationship: scorpion defensive behaviour and its relation to morphology and performance. Funct Ecol. 2017 Mar;31(7):1390-404.

25. 25. Rasko M, Coelho P, Simone Y, van der Meijden A. How to attack a scorpion: venom metering during a repeated attack. Anim Behav. 2018 Nov;145:125-9.

26. Polis, GA. Prey and feeding phenology of the desert sand scorpion Panuroctonus mesaensis (Scorpionidae: Vaejovidae). J Zool. 1979 Jul;188(3):333-46.

27. Polis GA, McCormick SJ. Scorpions, spiders and solpugids: predation and competition among distantly related taxa. Oecologia. 1986 Dec;71(1):111-6.

28. Miranda RJ, Bermúdez SE, Cleghorn J, Cambra RA. Presas de escorpiones (Arachnida: Scorpiones) de Panamá con observaciones sobre el comportamiento de depredación. Rev Iber Aracnol. 2015 Dec;27:115-23.

29. Davison AM, Brown TW, Arrivillaga C. Notes on the diet and reproduction of the bark scorpion Centruroides gracilis (Scorpiones: Buthidae) on Utila Island, Honduras. Euscorpius. 2020;2020(314):1-7.

30. González-Gómez JC, Valenzuela-Rojas JC, García LF, Franco-Pérez LM, Guevara G, Van Der Meijden A. Sexual dimorphism in the biomechanical and toxicological performance in prey incapacitation of two morphologically distinct scorpion species (Chactas sp. and Centruroides sp.). Biol J Linn Soc. 2020;129(1):190-8.

31. Toscano-Gadea CA, Costa FG. Is Tityus uruguayensis (Buthidae) an araneophagic scorpion? An experimental analysis of its predatory behaviour on spiders and insects. Bull Br Arachnol Soc. 2006;13(7):256-64.

32. Guerrero-Vargas JA, Buitrago JR, Ayerbe S, Daza Flórez E, Beltrán J T. Scorpionism and dangerous species of Colombia. Gopalakrishnakone P, Possani LD, Schwartz EF, Rodriguez De La Vega R, editors. Scorpion venoms. Dordrecht: Springer Netherlands. 2014.

33. Gómez JP, Otero R, Núñez V, Saldarriaga M, Díaz A, Velásquez P. Aspectos toxinológicos, clínicos y epidemiológicos del envenenamiento producido por el escorpión Tityus fuhrmanni Kraepelin. Medunab. 2002;5(15):159-65.

34. Rouaud C, Cloudsley-Thompson JL, Lourenco WR. The life history of Tityus fuhrmanni kraepelin (Scorpiones, Buthidae). Biogeographica. 2000;76(3):119-24.

35. Gómez JP, Velásquez P, Díaz A, Saldarriaga M, Otero R. Aspectos biológicos y ecológicos del escorpión Tityus fuhrmanni (Kraepelin, 1914), en poblaciones del cerro El Volador y barrios aledaños de la ciudad de Medellín. Act Biol. 2002;24(77):103-11.

36. McCormick SJ, Polis GA. Prey, predators, and parasites. The biology of Scorpions. 1990:294-320.

37. Eisner T, Eisner M, Siegler M. Secret weapons: defenses of insects, spiders, scorpions, and other many-legged creatures. Harvard University Press. 2005.

38. Bateman PW, Fleming PA. Increased susceptibility to predation for autotomized house crickets (Acheta domestica). Ethology. 2006 Jul;112(7):670-77.

39. Clark AJ, Triblehorn JD. Mechanical properties of the cuticles of three cockroach species that differ in their wind-evoked escape behavior. PeerJ. 2014 Jul 31;2:e501.

40. Schneider CA, Rasband WS, Eliceiri KW. NIH Image to ImageJ: 25 years of image analysis. Nat methods. 2012 Jun 28;9(7):671-5.

41. Pekár S, García LF, Viera C. Trophic niches and trophic adaptations of prey-specialized spiders from the Neotropics: a guide. In Behaviour and ecology of spiders. Springer. p. 247-274. 2017.

42. R Core Team. R: A language and environment for statistical computing. R Foundation for Statistical Computing, Vienna, Austria. 2020. https:// www.R-project.org/.

43. Blass GR, Gaffin DD. Light wavelength biases of scorpions. Anim behav. 2008 Aug;76(2):365-73.

44. Pekár S, Brabec M. Generalized estimating equations: A pragmatic and flexible approach to the marginal GLM modelling of correlated data in the behavioural sciences. Ethology. 2018;124(2):86-93. 
45. Munekiyo SM, Mackessy SP. Effects of temperature and storage conditions on the electrophoretic, toxic and enzymatic stability of venom components. Comp Biochem Physio B Biochem Mol Biol.1998 Jan;119(1):119-27.

46. Manzoli-Palma MF, Gobbi N, Palma MS. Insects as biological models to assay spider and scorpion venom toxicity. J Venom Anim Toxins. 2003;9(2):174-85. https://doi.org/10.1590/S1678-91992003000200004.

47. Quistad GB, Dennis PA, Skinner WS. Insecticidal activity of spider (Araneae), centipede (Chilopoda), scorpion (Scorpionida), and snake (Serpentes) venoms. J Econ Entomol.1992 Feb 1;85(1):33-9.

48. Tahir HM, Zafar K, Mishal R, Naseem S, Butt A, Yaqoob R, Arshad M. Potential use of venom of Odontobuthus odonturus (Arachnida: Buthidae) as bio-pesticide against Rhopalosiphum erysimi (Homoptera: Aphididae). Pak J Zool. 2015 Feb;47(1):37-40.

49. Van der Meijden, A, Koch B, van der Valk T, Vargas-Muñoz LJ, Estrada-Gómez S. Target-specificity in scorpions; comparing lethality of scorpion venoms across arthropods and vertebrates. Toxins (Basel). 2017 Oct;9(10):312.

50. Herzig V, John Ward R, Ferreira dos Santos W. Intersexual variations in the venom of the Brazilian 'armed' spider Phoneutria nigriventer (Keyserling, 1891). Toxicon. 2002 Oct;40(10):1399-406.

51. Richardson M, Pimenta AMC, Bemquerer MP, Santoro MM, Beirao PSL, Lima ME, Figueiredo SG, Bloch Jr C, Vasconcelos EAR, Campos FAP, Gomes PC, Cordeiro MN. Comparison of the partial proteomes of the venoms of Brazilian spiders of the genus Phoneutria. Comp Biochem Physiol C Toxicol Pharmacol. 2006 Mar-Apr;142(3-4):173-87.

52. Pekár S, Brabec M. Modern analysis of biological data: generalized linear models in R. Masarykova univerzita. 2016.

53. Formanowixz Jr DR. The antipredator efficacy of spider leg autotomy. Anim Behav. 1990;40(2):400-1.

54. Punzo F. Leg autotomy and avoidance behavior in response to a predator in the wolf spider, Schizocosa avida (Araneae, Lycosidae). J Arachnol. 1997;25(2):202-5.
55. Domenici P, Booth D, Blagburn JM, Bacon JP. Cockroaches keep predators guessing by using preferred escape trajectories. Curr Biol. $2008 \mathrm{Nov}$ 25;18(22):1792-6

56. García LF, Viera C, Pekár S. Comparison of the capture efficiency, prey processing, and nutrient extraction in a generalist and a specialist spider predator. Naturwissenschaften. 2018 Apr 2;105(3-4):1-10.

57. Mukherjee S, Heithaus MR. Dangerous prey and daring predators: a review. Biol Rev. 2013 Aug;88(3):550-63.

58. Albín A, Toscano-Gadea CA. Predation among armored arachnids: Bothriurus bonariensis (Scorpions, Bothriuridae) versus four species of harvestmen (Harvestmen, Gonyleptidae). Behav Process. 2015;121:1-7.

59. Scott JG, Matsumura F. Evidence for two types of toxic actions of pyrethroids on susceptible and DDT-resistant German cockroaches. Pest Biochem Physiol. 1983 Apr;19(2):141-50.

60. Wei Y, Appel AG, Moar WJ, Liu N. Pyrethroid resistance and crossresistance in the German cockroach, Blattella germanica $(\mathrm{L})$. Pest Manag Sci. 2001 Nov;57(11):1055-59.

61. Díaz C, Rivera J, Lomonte B, Bonilla F, Diego-García E, Camacho E, Tytgat J, Sasa M. Venom characterization of the bark scorpion Centruroides edwardsii (Gervais 1843): Composition, biochemical activities and in vivo toxicity for potential prey. Toxicon. 2019 Dec 5;171:7-19.

62. Young BA, Lee CE, Daley KM. Do snakes meter venom? Bioscience. 2002 Dec;52(12):1121-6.

63. Walker AA, Weirauch C, Fry BG, King GF. Venoms of heteropteran insects: a treasure trove of diverse pharmacological toolkits. Toxins. 2016;8(2):43.

64. Garb JE, Hayashi CY. Molecular evolution of a-latrotoxin, the exceptionally potent vertebrate neurotoxin in black widow spider venom. Mol Biol Evol. 2013 May;30(5):999-1014

65. Holding ML, Biardi JE, Gibbs HL. Coevolution of venom function and venom resistance in a rattlesnake predator and its squirrel prey. Proc Biol Sci. 2016 Apr 27;283(1829):20152841. 